\title{
EL MITO DE CARMEN: EXOTISMO, ROMANTICISMO E IDENTIDAD ${ }^{1}$
}

\author{
$\mathrm{M}^{\mathrm{a}}$ Teresa Vera Balanza \\ mvb@uma.es \\ Natalia Meléndez Malavé \\ natalia@uma.es
}

(Universidad de Málaga)

\section{Resumen:}

Este artículo propone un recorrido por las diferentes adaptaciones de la obra Carmen de Merimée, reconocida en el mundo entero como representación del ideal romántico de las mujeres hispanas. El texto hace hincapié en la pervivencia casi anti-histórica del mito, junto a la enfatización de los componentes identitarios, que enfrentan el progreso con el atraso endémico. Si en su origen Carmen revelaba la mirada foránea, actualmente su reproducción compete casi exclusivamente a autocomplacientes creaciones autóctonas, que hasta ahora no han aprovechado el conocimiento de la realidad española para recrear una versión más crítica.

Palabras clave: Mito, identidad, España, Andalucía, estereotipos.

\section{Abstract:}

This article proposes an itineray by the different adaptations from Merimée's Carmen, recognized in the entire world like the romantic representation of the ideal of Hispanic women. The text emphasizes the almost antihistorical continuity of the myth, the emphasis of the identity elements, that oppose the progress and the endemic underdevelopment. If in its origin Carmen revealed the foreign look, at the moment its reproduction is incumbent on almost exclusively to self-complacents native creations, that have not yet taken advantage from the knowledge of Spanish reality to recreate a more critical version.

Key words: Myth, identity, Spain, Andalusia, stereotypes.

\section{INTRODUCCIÓN}

\footnotetext{
1 Esta investigación forma parte del proyecto Personajes, acciones y escenarios andaluces en el cine español (1934-2007), financiado por la Fundación Centro de Estudios Andaluces.
} 
évi-Strauss (1987: 229-252) interpreta que los pueblos acuñan mitos para ayudar a suavizar las tensiones que resultan de las aparentes contradicciones entre las creencias y la práctica y reconcilian lo que debería ser con lo que realmente es. Interpretados unas veces como ensoñaciones de la conciencia colectiva, y otras como mecanismos de divinización de personajes históricos (o a la inversa), lo cierto es que los mitos recrean los sentimientos fundamentales de cualquier sociedad: el amor, el odio, la venganza. En tanto que esto es así, el valor intrínseco atribuido al mito proviene de que estos acontecimientos, que se suponen ocurridos en un tiempo pretérito, forman también una estructura permanente; se refieren, pues, simultáneamente al pasado, al presente y al futuro. Desde luego, la abundancia con la que ha sido recreado nuestro objeto de estudio corrobora este hecho.

Afirma también el antropólogo que la mitología es considerada un reflejo de la estructura social y de las relaciones sociales. Sin duda, y a pesar de las transformaciones narrativas, Carmen es esencialmente la historia de una relación triangular imposibilitada por obstáculos de clase, de raza y de sexo; la cigarrera, el soldado y el torero son arquetipos irreconciliables: uno representa el orden institucional, otro el tipo folklórico, la otra la transgresión, independientemente de que la historia se desarrolle en la España napoleónica o en los suburbios de Los Ángeles.

Cuando Prosper Mérimée conoció en 1830 a la Condesa de Montijo que le narró la historia del soldado que pierde profesión, fortuna y honra por una ardiente gitana, poco podía suponer que su interlocutora sería por ella misma objeto de leyenda al convertirse en la esposa de Luis Napoleón. Una y otra, la cigarrera y la emperatriz, en una suerte de asimilación constituían la resolución -al menos ficticia- de la larga rivalidad franco-española: si el siglo XIX se inicia con una invasión, llegado a su ecuador España pone a una española (granadina, andaluza, los matices se acentúan según las versiones) en el trono de Francia. Como si de un happy ending se tratara, el amor lo resuelve todo, si bien antes ya se había encargado de complicarlo.

Más allá de las leyendas, que suelen ser afirmaciones falsas, el mito de Carmen tiene componentes socio-históricos fundamentados y, no pocas veces, contradictorios. Si el Romanticismo -afirma Raymond Williams (1985)- surgió como una reacción frente al industrialismo, lo cual provocó un interés y una idealización de las sociedades preindustrales, resulta que nuestra Carmen es el prototipo de una nueva clase, un proletariado femenino con una enorme carga de rebeldía, formado por mujeres independientes en lo económico y sentimentalmente activas. El mito de Carmen es revolucionario en tanto destructora del orden social establecido y de las buenas costumbres burguesas. Pero más allá del mito romántico y folklórico, la realidad histórica es que la Fábrica de Tabacos de Sevilla era el más importante establecimiento industrial de la época en Andalucía, que el siglo XIX verá como se va proletarizando este sector de la actividad y, por ende, incrementándose la conflictividad nacida no ya de lances amorosos, sino de las condiciones de trabajo que culminará, entre 1918 y 1923, con la organización y sindicación en torno a la Sociedad de cigarreras y tabaqueros "Nicot" (Baena Luque, 1993).

Si la actividad laboral -originariamente cigarrera, luego cantante y bailarina, otras veces actriz de teatro y en una ocasión trabajadora en una fábrica de paracaídases una característica importante a la hora de definir a nuestra protagonista, el resto de personajes también vienen determinados por esta circunstancia; así, tanto el sol- 
dado como el torero -en estos casos, sí que se mantienen los roles- representan dos mundos distintos, el del poder frente a la fama y la fanfarria, pero, sin embargo, cuentan con un origen plebeyo común que queda diluido en sus respectivas ocupaciones. Esta asimilación entre tipos populares edulcora en alguna medida el componente trasgresor de una relación socialmente desigual, pero maximiza el matiz de género: Carmen elige y cambia de pareja, con ello provoca el conflicto pero esa actitud es expresión ineludible de su deseo, y de su voluntad, que será convenientemente castigado.

Desde luego, la narración de la mujer autónoma condenada por su rebeldía no nos es ajena, constituye el relato fundacional de nuestra cultura occidental. El castigo de la primera fémina fue la expulsión del lugar del mito y la entrada en el cronotipo de la Historia enmarcado en las coordenadas del mal, el sufrimiento y la muerte que se constituyen en materia del relato. Con ella asistimos a la condena de la mujer deseante de sabiduría y pasamos a la mujer definida por su función sexual (De la Concha, 2004: 17-29). En el caso de Carmen, el tipo histórico nos posibilita el camino inverso: los actantes originarios pasaron a la esfera del mito pero recibieron, igualmente, el consiguiente correctivo. Culturalmente, el siglo XIX aprovechó el género novelístico por su capacidad de seducción y por su discurso persuasivo (Armstrong, 1991); con la novela, el suplicio ya no es físicamente necesario y el nuevo arte de castigar, afirma Foucault (1994), se basa en la representación, donde el autor se vuelve moralista y el mecanismo disuasorio funciona eficazmente por absoluta represión del deseo. Aunando cualidades, el efecto se multiplica iniciado el siglo XX: la novela muestra los hechos y establece el juicio moral, el cine fija las imágenes y determina los mecanismos de decodificación del mensaje.

\section{UN CENTENAR DE CÁRMENES Y UN DISCURSO UNITARIO}

Como ningún otro personaje, nuestra protagonista ha sido objeto predilecto de los guiones cinematográficos. Lo atestiguan más de cincuenta adaptaciones al cine y a la televisión, grabaciones de las representaciones operísticas y de los ballets que han recreado la historia de la gitana. Sin duda, la historia contenía los suficientes elementos expresivos como para llevarla al soporte fílmico, así la época muda contó con 18 adaptaciones de la novela de Mérimée: la primera, una producción italiana de 1909 dirigida por Gerolamo Lo Savio, y la última una película alemana de animación -mediante sombras chinescas- dirigida por Lotte Reininger en 1933. Entretanto, los más famosos directores y actrices de la etapa muda abordaron el tema. Así, 1915 fue un año prolífico en producciones: Cecil B. de Mille reúne en su versión de Carmen a Geraldine Farrar, Wallace Reid y, como genuino representante del genio español, a Pedro de Córdoba; Theda Bara encarna a la protagonista del film de Raoul Walsh ${ }^{2}$ y Edna Purviance a la de la parodia de Chaplin Burlesque on Carmen, que tendría al año siguiente una versión rotulada en castellano para Argentina, Portugal y España. En 1918, Ernst Lubitsch rueda su versión de Carmen, protagonizada por Pola Negri. Sin duda, la expresividad de las actrices, imprescindible antes de la llegada del sonoro, se refuerza en esta historia dramática de amores y celos, de honor y de

\footnotetext{
2 El director retoma el tema en The loves of Carmen, de 1927, para la que elige a la mejicana Dolores del Río y al estadounidense de idéntico origen Don Alvarado, sin duda para incrementar las connotaciones raciales de los personajes.
} 
flirteos.

Pero no sólo las producciones estadounidenses y alemanas, cabezas de la industria en esta época, recrean el mito; producciones austriacas ${ }^{3}$, holandesas ${ }^{4}$, soviéticas $^{5}$, y británicas ${ }^{6}$ comparten el mismo argumento. Lógicamente también Francia y España (y Méjico, como avanzadilla hispana en Norteamérica), como nacionalidades protagonistas, se interesan por la trama romántica. La producción española más antigua es Carmen o la hija del contrabandista (1911) dirigida por Ricardo de Baños y Alberto Marro e interpretada por Concha Lorente, a la que le sigue la coproducción italo-española Carmen (1913), dirigida por Giovanni Doria y Augusto Turqui y con reparto mixto compuesto por Andrea Habay, Juan Rovira, Suzy Prim y Margarita Silva. Del otro lado del Atlántico, cabe destacar la Carmen del mexicano Ernesto Vollrath (1921) y la producción peruana de 1928 La Perricholi que recrea idéntica trama pero refuerza los elementos coloniales ${ }^{7}$. Francia retoma la obra de Mérimée con el film Carmen (1926) de Jacques Feyder con Raquel Meller (que enfatiza las secuencias de danza), Louis Larch, Gaston Modot en el papel de García "el tuerto" -esposo de Carmen que en la ópera de Bizet pierde protagonismo para cedérselo al torero-y una brevísima intervención de Luis Buñuel.

La etapa sonora se inicia con una de las más famosas adaptaciones, la que protagonizara Imperio Argentina. Evidentemente esta etapa debía estar determinada por los recursos del sonido, lo que supuso la primacía de la versión musical de Bizet frente al relato viajero de Mérimée cuya estructura narrativa hubiera tenido que apostar por un flash-back completo donde, como en la novela, José Lizarrabengoitia relataba su aventura al arqueólogo francés (cargo que el autor realmente desempeñó en España antes de ser nombrado senador por Napoleón III). Así en la Alemania de 1938 se rueda la doble versión protagonizada por Imperio Argentina y recreada en el film La niña de tus ojos de Fernando Trueba: Carmen, la de Triana, bajo la dirección de Florián Rey y Andalusische Nächte, dirigida por Herbert Maisch y doblada al inglés (Nights in Andalusia, 1938) para el mercado estadounidense. Los títulos que evitan la concisa aunque explícita referencia a Carmen tienen un sentido plenamente contextualizado: en el primer caso, porque se opta por el genérico andaluz como representación de lo español; en el segundo, porque así se evita la alusión a Carmen como prototipo de una raza no aria cuyo peso en la narración es más que evidente. Uno y otro eliminan las aristas más incómodas en la configuración de los personajes y dulcifican el drama en beneficio de los aspectos musicales y de los ideales propagandísticos. Podemos ver, así, que se persevera en la tesis de Martín Barbero

3 Die Venus (1922), dirigida por Hans Homma e interpretada por el trío formado por Magda Sonja, Raoul Aslan y Robert Balajthy.

4 Een Carmen van het Noorden (1919), dirigida por Maurits Binger y Hans Nesra.

5 Medvezhya Svadba (1926), dirigida por Konstantin Eggert y Vladimir Gardin.

6 Carmen (1912), dirigida por Theo Frankel y Carmen: Gipsy Blood (1931), dirigida por Cecil Lewis.

${ }^{7}$ La misma versión se recrea en La carrose d'or de Jean Renoir (1953), interpretada por Anna Magnani, donde la protagonista, que ya no es Carmen sino Camilla y en vez de cigarrera es actriz, se debate ahora entre tres hombres, pues se une al dueto entre el soldado y el torero un nuevo personaje, en este caso el virrey. 
(1987) cuando sostiene que el proyecto de construcción de las naciones modernas en los treinta se articula sobre tres bases: un movimiento económico determinado por la entrada de las economías nacionales en el mercado internacional; un proyecto político de construcción de las naciones mediante la creación de una cultura, una identidad y un sentimiento nacional; y, consecuentemente, la instrumentalización de los medios de comunicación, especialmente la radio y el cine, para dichas tareas. Nada más apropiado pues que estos productos-mensajes que buscan la aceptación del público mediante un mecanismo de novedad/reconocimiento sustentado sobre la representación de estereotipos: unos renovados en función de las cambiantes circunstancias geopolíticas y otros preservados de tales dinámicas y anclados -como mencionábamos- en una estructura visual que enfatiza unos valores identitarios donde populismo y nacionalismo se hibridan a la perfección. De esta manera lo hispano se españoliza y lo español se identifica con los elementos tipificados -desde el siglo XVIII y a ojos de observadores externos- como andaluces: gitanas fogosas, toreros valientes, coplas y rejas,... como elementos que van y vienen, reubicados en Sevilla, en Madrid, en Ronda o, por extensión, en Méjico o en Los Ángeles.

Así, a partir de entonces, cada década ha tenido sus tres o cuatro adaptaciones de la historia; unas más apegadas a la novela de Mérimée y otras más fieles a la ópera. En general, han sido los franceses los más propensos a la recreación literaria, mientras que estadounidenses y españoles han preferido el libreto musical; la grabación de las óperas y las realizaciones para televisión multiplicaron el número de producciones a partir de la década de los 60 . No obstante, frente a las similitudes sería necesario abordar aquellas películas cuya originalidad residió no tanto en el hilo argumental, que es prácticamente idéntico, sino precisamente en la incorporación de aspectos, matices y elementos diferenciales en general. Por ejemplo, Charles Vidor en The loves of Carmen (1948) aprovecha las cualidades musicales de Rita Hayworth y, sobre todo rentabiliza el éxito comercial de Gilda, al enfrentarla por segunda vez a Glenn Ford: la frialdad y la contención del estadounidense frente a la apasionada y sensual hispana en una historia que, además, se rodó por primera vez en technicolor maximizando las capacidades artísticas de la bailarina y su voluptuosa cabellera rojiza. Ya en la iconografía pictórica la cabellera suelta, los mechones desordenados o el peinado desaliñado, se ha correspondido con mujeres de clases populares y se ha interpretado en claves de seducción, tal y como hiciera Romero de Torres. El cabello sobre la cara, ocultador y reclamo de una personalidad turbulenta pero enormemente seductora, tuvo sus máximas representantes cinematográficas en Lauren Bacall y Veronica Lake.

En España, la siguiente versión de Carmen, ya en color, fue Carmen, la de Ronda (1959), dirigida por Tulio Demicheli e interpretada por Sara Montiel. El cambio de circunscripción geográfica -de Triana a Ronda- no era una novedad; el relato original, como todo libro de viajes, transitaba de Sevilla a Córdoba y terminaba en Sierra Morena, donde el oficial, convertido ahora en bandolero, contaba su historia. El distintivo de esta versión es que el oficial es francés, y no vasco, con lo que se evitaba el conflicto de los nacionalismos, y estaba interpretado, empero, por el actor francés Maurice Ronet, magnífico oponente al galán latino de los cincuenta Jorge Mistral que remedaba al bandolero. Así, la historia carga las tintas en la ocupación francesa y nuestra Carmen se muestra como un híbrido entre su propio personaje y el de Agustina de Aragón, ambas utilizan sus armas de seducción en las tareas de resistencia. Este giro lo confirma la versión norteamericana de 1962, que se titulaba ex- 
plícitamente $A$ girl against Napoleon.

Otra particular versión es Carmen Jones (1954) dirigida por Otto Preminger, con adaptación de la partitura de Bizet de Gilbert, Birnbaum y Brand. Kleiner y Oscar Hammerstein II convirtieron a los personajes en hombres y mujeres de color -si bien la película se rueda en blanco y negro- y situaron la acción en Los Ángeles, meses después de que el Tribunal Supremo prohibiera la segregación racial en las escuelas estadounidenses. Protagonizada por Dorothy Dandrige -doblada por Marilyn Horne-, Carmen trabaja en una fábrica de paracaídas donde se enamora de un sargento interpretado por Harry Belafonte y flirtea con un galán, interpretado por Joe Adams, que es boxeador. El espectáculo taurino se sustituye en esta ocasión por el pugilístico. Como el fútbol o los toros en un principio y en latitudes meridionales, el boxeo para los afroamericanos -y el ejército en los escalafones inferiores- era la actividad más factible para superar los desniveles de clase. A pesar de la traslación racial, se elude el conflicto desde el instante en que se prefiere no introducir a personajes blancos que interfieran en la historia. Musicalmente, los arreglos son jazzísticos imprimiendo así un particular toque folklórico a esta adaptación.

La prevalencia de este drama en el género musical se mantiene tanto en producciones cinematográficas como televisivas en las décadas de los 60 y 70 , hasta llegar al año 1983 donde confluyen dos versiones contrapuestas. Insistiendo una vez más en el antagonismo entre España y Francia, se estrenan simultáneamente la Carmen de Carlos Saura y Prénom Carmen de Jean-Luc Godard. En la primera, la ópera se mezcla con temas de Paco de Lucía y está co-interpreteda por Laura del Sol y Antonio Gades, resaltando así la lectura flamenca del hilo argumental. La otra es una adaptación libérrima donde Maruscha Detmers da vida a Carmen X, integrante de un grupo terrorista que se enamora de un joven policía que vigila la entidad bancaria que pretenden asaltar; aquí, la protagonista se limita a silbar la Canción del toreador, para dar primacía musical a los Cuartetos de Beethoven.

Con todo, en este breve recorrido hemos observado a cármenes que cantan, que bailan, que seducen, pero no hablan. No nos referimos sólo a la etapa muda del cinematógrafo, lo hacemos desde un punto de vista discursivo en el sentido en que la protagonista no es autónoma, es el trofeo por el que rivalizan los actantes masculinos. Como en el relato originario, el discurso autolegitimador es el de un narrador masculino y Carmen es el desencadenante.

Frente a esa homogeneidad, precisamente despunta Carmen: a hip-hopera (2001) de Robert Townsend; no tanto por el color del reparto sino por el elemento identitario del grupo representado en los arreglos musicales y particularmente por la actitud de la protagonista. No destaca precisamente Beyoncé Knwoles, su intérprete principal, por sus rasgos afroamericanos y aún menos con su larga cabellera rubia. No es tampoco la primera vez que lo racial se adecua a otros contextos geopolíticos ${ }^{8}$. Pero sí que la propuesta narrativa experimenta cierta transformación en la adaptación musical. Y es que Carmen Brown relata -porque rapea- sus pensamientos y sus

\footnotetext{
8 La tercera adaptación con una mujer negra en el papel de Carmen se realizó en Senegal bajo el título Karmen Gei (2001) y dirección de Joseph Gaï Ramaka, donde se abordan en un contexto totalmente excepcional las relaciones lésbicas. Otra versión reciente es la sudafricana U-Carmen eKhoylitsha del realizador británico Mark Domford-May, ganadora del Oso de Oro del Festival de Cine de Berlín en 2006.
} 
opiniones; toma la iniciativa en este diálogo de seducción y de rebelión y acompaña esta actitud de una impronta gestual -la del baile, la de la banda- que enfatiza su determinación: I have a dream... you know, parafraseando a Martín Luther King. La historia se presenta, asimismo, en clave de cuento donde una rapera expone la trama y concluye con un epilogo moral: Carmen Brown, sad tale of a life cut short (Feenstra, 2005: 84-93).

La construcción del mito (Amossy, 1991) pasa, pues, por una fase de estereotipificación donde perviven, pese a todo, los símbolos menos amenazadores: el exotismo y la sensualidad sobre la rebeldía y la fortaleza. Las muestras más recientes avalan nuestra hipótesis.

\section{LA PERSEVERANCIA DEL MITO: CARMEN DE VICENTE ARANDA}

En 2003, Vicente Aranda estrena una nueva versión de Carmen. Imbuida de las constantes del realizador, es esta penúltima versión a través de la cual el público más joven se acercará a este estereotipo de feminidad y españolidad. Porque se trata de una de las versiones más fieles a la obra original de Mérimée -flash-back narrativo, idénticos escenarios itinerantes, recuperación de la figura del marido de Carmen-, esta película adolece de ser una recreación sin reflexión sobre el sentido último de la novela: la mirada extranjera sobre la realidad hispana, desaprovechando, una vez más, la oportunidad de cuestionar la construcción identitaria del relato; si bien tiene el acierto de huir de los aspectos folklóricos.

No obstante una visión acrítica de la novela hace aflorar ciertos tópicos tanto en la protagonista como en su entorno. Colmeiro defiende la tesis, creemos que muy acertada, de que Carmen ha contribuido a una persistente y extendida noción de España como nación oriental. Este mito, una de nuestras mercancías simbólicas más reconocibles, constituye el legado de la fantasía romántica de España como tierra de pasión, viajes exóticos y placeres eróticos, pero también esencialmente diferente, excéntrica, primitiva e inferior. Esta imagen deformada -reducción metonímica que identifica lo hispano con lo español en un proceso de unificación que se cobra como primera víctima a lo andaluz- no sólo ha circulado entre los extranjeros, sino que también ha sido explotada por los propios españoles, de manera tan insistente que se hace muy difícil romper el encanto que ejerce Carmen en la definición de lo español (Colmeiro, 2003: 57-83). En esa línea, podemos establecer un pequeño inventario de evocaciones de la cultura española como mezcla de civilizaciones exóticas y legendarias.

En primer lugar, la fascinación del extranjero que viaja por España. Es el propio Mérimée el que confiesa al comienzo de la película que buscaba información sobre las dinastías omeya y nazarí en dos capitales históricas del Islam, Córdoba y Granada. Así incluye escenas que subrayan las huellas de un pasado esplendoroso, como el hallazgo de una pieza en una excavación arqueológica o la secuencia ambientada en la Mezquita cordobesa. El propio edificio es una metáfora de la España de pasado árabe sobre la que se cimienta la España católica -llena también de superstición y lecturas folklóricas de lo religioso.

Justamente, en segundo término, la variedad de creencias de los personajes re- 
salta el carácter heterogéneo de lo español: don José, católico ferviente, visita la Iglesia con frecuencia mostrando la curiosa relación de los españoles con las imágenes veneradas, que tanto asombra a los extranjeros por lo exacerbado de las manifestaciones de una espiritualidad barroca, sustentada -como todo lo recién convertido- en mero ejercicio de ostentación. Por el contrario, pero de la misma forma expresiva, Carmen se jacta de ser sierva de Satanás y practica toda clase de ritos oscuros de adivinación y sortilegios maléficos. La mezcla de ambas creencias se hace evidente en la dueña del burdel, que echa las cartas con la misma naturalidad con que pone velas a una Virgen o se santigua. En ella, como en el país mítico que se nos intenta transmitir, conviven sin empacho todo tipo de cultos misteriosos.

Conjugando todos estos aspectos exóticos, la piedra angular del relato es un personaje dominado por la contradicción: esta Carmen reniega de la raza gitana ya desde la primera secuencia; sin embargo, es de los gitanos de quienes ha recibido el modo de vida sin ataduras del que no está dispuesta a prescindir, pese a los requerimientos de don José. Pero aquí aparece una segunda contradicción, pues a pesar de su deseo constante de libertad, que se traduce en una existencia marginal, Carmen se siente también atraída por ciertas manifestaciones de boato que sólo el modo de vida burgués puede proporcionarle. Ello se percibe, por ejemplo, en su apego al recatado vestido blanco que trae de la emboscada urdida por su marido (que le quita el delicado sombrero de un manotazo) o en su presencia en la plaza de toros y su atracción por el torero Lucas Domecque, quien representa las más altas cotas de éxito, lujo y aceptación social de la época, y cuyo apellido rememora a una oligarquía andaluza fraguada sobre la propiedad de la tierra e impulsada por los vínculos externos que son los de las relaciones comerciales.

Como justificación de estas contradicciones, la Carmen que interpreta Paz Vega es el producto de una trayectoria vital sembrada de innumerables cicatrices emocionales y físicas que marcan sus relaciones con los hombres. Este sombrío pasado, contado a don José por la dueña del burdel, contribuye a hacer algo más compresible un comportamiento que, en otras versiones, la exhibe como voluble y carente de motivación. Esta Carmen -quizá la más agresiva y hosca, la menos festiva, debido a la ya mencionada renuncia al folklorismo- presenta el carácter práctico, más apegado a la realidad, de quien ha tenido que aprender a subsistir en las calles. Además de esta aportación novedosa y alguna otra como la masculinización del personaje representada en su plena integración en el grupo de bandoleros, desenvolviéndose con ellos en la sierra en igualdad de condiciones, montando su propio caballo, participando en los asaltos e incluso dejándose ver manteniendo relaciones sexuales, etc., encontramos también algunos toques algo ingenuos, o al menos, poco sutiles: por ejemplo, la variedad de trabajos plagados de tipismo que simultanea (además de, como es razonable, en la fábrica de tabacos la vemos como bailarina, echadora de cartas, prostituta y contrabandista) o también la insistencia en su primitivismo y su sensualidad tentadora haciéndola aparecer hasta tres veces mordiendo fruta fresca.

En cualquier caso, no nos pasan desapercibidas las claves simbólicas que se utilizan para adornar al personaje como una Eva moderna (Andreu Miralles, 2004): Carmen toma la fruta, seduce a don José atravesando la calle Sierpes y lo incita a adentrarse en el camino del mal, de tal modo que el soldado acaba trasponiendo su adoración mariana hacia su amada. Ángeles y demonios, vírgenes y seductoras, son dualidades inherentes a la construcción literaria del Romanticismo. En este sen- 
tido, Carmen es una mujer hechicera, de encanto irresistible que aboca a la perdición, domina la brujería y dice tener tratos con Satanás e incluso se dice de ella que habita en el infierno. Además, la identificación con esta mujer demoníaca se refuerza con la evocación de uno de los escritores románticos que en mayor medida contribuyó a crear el arquetipo de la diablesa. En un momento de la película, Carmen entona con fines seductores una canción que es precisamente la rima XXII de Gustavo Adolfo Bécquer: Por una mirada, un mundo. Todo este juego de ritos oscuros y tácticas de seducción refuerzan la interpretación orientalista de lo castizo.

Otro guiño romántico lo encontramos en la definición de la mujer andaluza de la que Mérimée se sirve para describir a Carmen: Tres cosas negras: los ojos, las cejas y las pestañas. Tres blancas: el cutis, los dientes y las manos. Tres sonrosadas: los labios, las mejillas, las uñas (La Ilusión, 1850). Y que no es otra que la primera definición de mujer objeto publicada en la prensa femenina española (Jiménez Morell, 1992). Tampoco podemos obviar la música que suena en el admirado reloj de Mérimée que no sólo es contemplado, desde el atraso español, como una innovación tecnológica traída por el progreso foráneo, sino que deleita a los nativos con el Para Elisa de Beethoven, cumbre del romanticismo musical.

Desde nuestro punto de vista, pese a los aciertos reseñados en la construcción del personaje, la película desaprovecha la ocasión de realizar una lectura enraizada en las circunstancias históricas y sociales de la España que se representa, alejándola de una imagen parcial de la realidad. Indudablemente, el contexto se inscribe en el proceso de asentamiento tardío de las revoluciones liberales ralentizada por el neocatolicismo imperante, malinterpretado por el francés -que no en vano se llamaba Próspero- como singularidad racial de unas gentes atadas a un destino inmutable por su terquedad en permanecer ajenos a la civilización y al progreso.

Así pues, nuevamente esta Carmen reedita la paradoja entre dos tópicos de lo español, a los ojos del extranjero, y de lo andaluz visto por el resto de identidades españolas o como generalización de lo hispánico, tal y como muestra, por ejemplo, que sea la Carmen de Vicente Aranda la película seleccionada como representación de Andalucía en una obra que propone un recorrido cinematográfico por cada una de las comunidades autónomas en la reciente producción española (Pérez Romero, 2006: 41-58). Indefectiblemente, nos reencontramos con los escenarios y actitudes festivas, el reiterado tópico de la alegría, la broma y la simpatía, acompañadas siempre de ecos musicales, baile y cante. Si bien, en una de las escenas, al otro lado de la guitarra un bandolero oculta un trabuco, imagen de la otra cara de la identidad que se nos presenta: la fatalidad, la violencia, los celos y la posesión, la pasión y la muerte, a las que aboca el primitivismo de los personajes.

\section{SECUELAS MANIERISTAS}

Engrosando la tendencia, a cada recreación dramática ha seguido la musical que conjuga, ya en este siglo, la faceta lírica y la danza. En 2001, Jérôme Savary y Gérard Deguerre idean una ópera bufa interpretada por Cristina Hoyos; optan por una composición anacrónica donde conviven los personajes del relato originario con Franco, Hemingway o Ava Gadner, y arreglos musicales jazzísticos y latinos con 
temas de Jacques Brel, Cole Porter o Paquito el Chocolatero ${ }^{9}$. La adición de referentes y el sincretismo musical no mejoró la composición y el resultado no obtuvo precisamente los favores de la crítica, pero logró la polémica de un montaje trasgresor que remedaba, sin disimulo alguno, un universo almodovariano: los amores homosexuales de la cigarrera, toreros enanos, guardias civiles travestidos, la bulimia carcelaria de Escamillo, etc., para una Carmen resucitada gracias a un trasplante de corazón -el de don José- realizado por el Dr. Barnard. De esta manera, dos siglos después la mirada de Merimée se trastoca por una visión insurrecta, solamente creíble cuando se reconocen los fundamentos sociales y culturales que la inspiran, y no cuando la galería kitsch se queda en la mera provocación.

En 2004, Salvador Távora presenta con su compañía La Cuadra de Sevilla, una nueva versión de Carmen que subtitula "Ópera Andaluza de Cornetas y Tambores". Aunque no dudamos del compromiso regionalista de Távora, la aleación de instrumentos nos pone sobre aviso de los referentes religioso-culturales de la adaptación. Con la intención de renovar el relato, apuesta por recuperar las narraciones populares y el componente subversivo del contexto: en la narración se rememora a Riego y al pensamiento liberal del primer tercio del siglo XIX donde Carmen se yergue como una mujer libre, independiente económicamente que se une, al margen del registro civil o la bendición eclesiástica, al militar vasco. En una última vuelta de tuerca, cierra su espectáculo con la ejecución de Lizarrabengoa, reinterpretándolo como un alegato actual contra la violencia machista. La apuesta por la libertad y la dignidad de los personajes enraizada en una cultura popular resistente frente a las imposiciones hegemónicas, no puede sustentar el forzado aggiornamento.

Por último, en otoño de 2007 Sara Baras estrenó su versión de Carmen destacando los aspectos más sutiles, elegantes y tiernos. Consecuente reacción a la deriva experimentada, el espectáculo se hace estéticamente más refinado. La música compagina la fidelidad a Bizet con temas de Paco de Lucía o de Javier Ruibal, verdaderos renovadores de la música andaluza con un origen ortodoxo común: uno como intérprete flamenco y el otro como compositor de coplas.

Como vaticinara Merimée y confirma la construcción mítica, la capacidad de Carmen para adecuarse a contextos cambiantes es sorprendente. Si en dos siglos el discurso ha pervivido, ahora coincidiendo con la conmemoración del bicentenario de la Guerra de la Independencia, la oportunidad estaría más que asegurada para transformar la identidad-resistencia en identidad-proyecto (Moreno, 2002: 219-225). Desde los eventos que recuerdan la ocupación napoleónica de 1808 a la promulgación de la Constitución liberal de 1812, asistimos nuevamente a la metáfora de la dialéctica entre absolutismo y progreso, acción y reacción, autocracia y estado liberal representados en nuestros arquetípicos protagonistas, pero desvestidos de cualquier matiz reivindicativo y sumidos una vez más en el tipismo y la escenografía: una ópera en Móstoles, un pasacalles por las plazuelas gaditanas. Más allá de la traslación cronológica, los contextos referenciales son otros pero lastran de nuevo el sentido. Si los fastos del 92 celebraban el nacionalismo español y la incorporación

\footnotetext{
9 El pasodoble del maestro Gustavo Pascual Falcó, compuesto en 1937 para ser interpretado en las fiestas de Moros y Cristianos, es una de las canciones que ha generado más derechos de autor en los últimos años en actuaciones en directo y ejecutadas por músicos en fiestas de pueblos, verbenas y demás celebraciones, según datos de la Sociedad General de Autores (SGAE).
} 
a la historia universal, los del 2008-2012 parecen haber eliminado la acción popular contra la tiranía y aclaman, a toda costa, la construcción europeísta sobre la base de un personaje extravagante para foráneos y denostado por autóctonos.

\section{REFERENCIAS BIBLIOGRÁFICAS}

AMOSSY, R. Les idées reçues. Sémiologie du stereotype. París: Nathan, 1991.

ANDREU MIRALLES, X. La mirada de Carmen: el mito oriental de España y la identidad nacional. En BERAMENDI, J. (coord.) Memorias e identidades: VII Congreso da Asociación de Historia Contemporánea, Universidade Santiago de Compostela, 2004.

ARMSTRONG, N. Deseo y ficción doméstica. Una historia política de la novela. Madrid: Cátedra, 1991.

BAENA LUQUE, E. Las cigarreras sevillanas. Un mito en declive (1887-1923). Málaga: Universidad de Málaga. Atenea, Estudios sobre la Mujer, 1993.

COLMEIRO, J. F. "El Oriente comienza en los Pirineos (La construcción orientalista de Carmen)". Revista de Occidente, 2003, n² 264, pp. 57-83.

DE LA CONCHA, Á. La dialéctica del deseo femenino y su representación literaria. En DE LA PASCUA, M. J.; GARCÍA-DONCEL, M.R. y ESPIGADO, G. (Eds.) Mujer y deseo: representaciones y prácticas de vida. Cádiz: Universidad de Cádiz, 2004, pp. 17-29.

FEENSTRA, P. "Mitos "españoles" y cuerpos exóticos: Carmen Jones (1954) y Carmen: a Hip Hopera (2001)". Archivos de la Filmoteca. Revista de estudios históricos sobre la imagen, 2005, n 51, pp. 84-93.

FOUCAULT, M. Vigilar y castigar. Madrid: Siglo XXI, 1994.

JIMÉNEZ MORELL, I. La prensa femenina en España: desde sus orígenes a 1868. Madrid: Ediciones de la Torre, 1992.

LÉVI-STRAUSS, C. Antropología estructural. Barcelona: Paidós, 1987.

MARTÍN BARBERO, J. De los medios a las mediaciones. Méjico: Gustavo Gili, 1987.

MORENO, I. La globalización y Andalucía. Entre el mercado y la identidad. Sevilla: Mergablum, 2002.

PÉREZ ROMERO, E. En mitad del camino. Paisajes y sentimientos de las Españas en nuestro cine (1975-2005). Cáceres: Filmoteca Regional de Extremadura/Festival del Cine Español de Cáceres, 2006.

WILLIAMS, R. Culture and Society, 1780-1950. London: Penguin Books, 1985. 


\section{Breve semblanza de las autoras}

$\mathbf{M}^{\mathbf{a}}$ Teresa Vera Balanza es Profesora Contratada Doctora en la Facultad de Ciencias de la Comunicación e Integrante del Seminario de Estudios Interdisciplinarios de la Mujer de la Universidad de Málaga. Especialista en Teorías de la comunicación y en Estudios de gênero, participa en el Programa de Doctorado interdisciplinar "Relaciones de género, sociedad y cultura en el ámbito mediterráneo" y en el proyecto "Representación del trabajo de las mujeres en los medios de comunicación: de la marginación a la utilización de Internet para la participación en la construcción de conocimiento y evaluación de políticas públicas".

Natalia Meléndez Malavé es Doctora en Periodismo y Profesora Ayudante en la Facultad de Ciencias de la Comunicación de la Universidad de Málaga. Especialista en Historia de la Comunicación y Documentación informativa, sus líneas de investigación giran en torno al estudio de la imagen en los medios y a diversas formas de comunicación alternativa y popular. Es miembro del "Grupo de Estudios sobre Comunicación y Sociedad de la Información en Andalucía".

(Recibido el 29-12-07, aceptado el 30-03-08) 